\title{
Met degradation by SAIT301, a Met monoclonal antibody, reduces the invasion and migration of nasopharyngeal cancer cells via inhibition of EGR-1 expression
}

\author{
B-S Lee ${ }^{1,2,5}$, S Kang ${ }^{1,2,3,5}$, K-A Kim $^{4}$, Y-J Song ${ }^{4}$, KH Cheong ${ }^{4}$, H-Y Cha ${ }^{1,2}$ and C-H Kim ${ }^{\star, 1,2,3}$
}

Nasopharyngeal carcinoma (NPC) is a common malignant tumor with high invasive and metastatic potential. The hepatocyte growth factor (HGF)-Met signaling pathway has a critical role in mediating the invasive growth of many different types of cancer, including head and neck squamous cell carcinoma. HGF also stimulates NPC cell growth and invasion in the cell line model. In this study, we determined the inhibitory effect of Met, using a Met-targeting monoclonal antibody (SAIT301), on the invasive and growth potential of NPC cell lines. Met inhibition by SAIT301 resulted in highly significant inhibition of cell migration and invasion in both the HONE1 and HNE1 cell lines. In addition, we also found that co-treatment of SAIT301 and HGF decreased the anchorage-independent growth induced by HGF in HNE1 cell lines. After SAIT301 treatment, Met, together with its downstream signaling proteins, showed downregulation of p-Met and p-ERK, but not p-AKT, in both HONE1 and HNE1 cell lines. Interestingly, we found that HGF treatment of NPC cell lines induced early growth response protein (EGR-1) expression, which is involved in cell migration and invasion. In addition, co-treatment with SAIT301 and HGF inhibited the HGF-induced expression of EGR-1. Next, knockdown of EGR-1 using small-interfering RNA inhibited HGF-induced cell invasion in NPC cell lines, suggesting that the expression level of EGR-1 is important in HGF-induced cell invasion of NPC cells. Therefore, the results support that SAIT301 inhibited Met activation as well as the downstream EGR-1 expression and could have therapeutic potential in NPC. Taken together, we suggest that Met is an anticancer therapeutic target for NPC that warrants further investigation and clinical trials and SAIT301 may be a promising tool for NPC therapy.

Cell Death and Disease (2014) 5, e1159; doi:10.1038/cddis.2014.119; published online 10 April 2014

Subject Category: Cancer

Nasopharyngeal carcinoma (NPC) is malignant tumor that occurs in the epithelial lining of the nasopharynx, and has a high incidence in southern China, Southeast Asia, Alaska and North Africa. ${ }^{1}$ The majority of patients with NPC are diagnosed as advanced disease with extremely common nodal metastasis. According to other papers previously published, at least $95 \%$ of NPC tumors regardless of histologic subtype have comorbid Epstein-Barr virus (EBV) infection $^{1}$ that is highly invasive and metastatic and differs from other head and neck cancers. ${ }^{2}$ These tumorigenic and invasive potential of EBV are due to an unique set of latent genes: latent membrane proteins and EBV-determined nuclear antigens are the proteins predominantly expressed in NPC. ${ }^{3}$ Especially, latent membrane proteins expression causes NPC cells to become migratory and invasive. ${ }^{4}$ Unfortunately, the mechanism of NPC metastasis is not fully determined. While recent therapies for NPC include radiation and chemotherapy, ${ }^{5}$ radioresistance remains a problem for successful clinical treatment.

Met, a proto-oncogene product receptor tyrosine kinase, is a specific receptor for hepatocyte growth factor (HGF), a cytokine of mesenchymal origin regulating various developmental processes by mediating epithelial-mesenchymal interaction. ${ }^{6}$ The Met proto-oncogene, initially identified as a transforming gene from a chemically induced human osteogenic sarcoma cell line, ${ }^{7}$ encodes a transmembrane glycoprotein with unique features composed of two disulfide-linked chains of a $50-\mathrm{kDa} \alpha$ subunit and a $145-\mathrm{kDa}$ $\beta$ subunit. ${ }^{8}$ The $\alpha$ subunit is heavily glycosylated and extracellular. The $\beta$ subunit consists of an extracellular portion involved in ligand binding, a membrane-spanning segment and a cytoplasmic tyrosine kinase domain. The kinase domain contains critical phosphorylation sites regulating its kinase activity. 9,10

\footnotetext{
${ }^{1}$ Department of Otolaryngology, Ajou University, Suwon, Republic of Korea; ${ }^{2}$ Center for Cell Death Regulating Biodrug, School of Medicine, Ajou University, Suwon, Republic of Korea; ${ }^{3}$ Department of Molecular Science and Technology, Ajou University, Suwon, Republic of Korea and ${ }^{4}$ Bio Therapeutics Lab, Samsung Advanced Institute of Technology (SAIT)/Samsung Electronics Co. Ltd, Yongin, Republic of Korea

${ }^{*}$ Corresponding author: C-H Kim, Department of Otolaryngology, Center for Cell Death Regulating Biodrug, Ajou University School of Medicine, 164, World cup-ro, Yeongtong-Gu, Suwon 443-380, Republic of Korea. Tel: +82 31219 5269; Fax: +82 31219 5264; E-mail: ostium @ ajou.ac.kr

${ }^{5}$ These authors contributed equally to this work.

Keywords: SAIT301; Met; invasion; migration; EGR-1; nasopharyngeal carcinoma

Abbreviations: EBV, Epstein-Barr virus; EGR-1, early growth response protein; EMT, epithelial-mesenchymal transition; HGF, hepatocyte growth factor; NPC, nasopharyngeal carcinoma

Received 13.1.14; revised 20.2.14; accepted 21.2.14; Edited by A Stephanou
} 
HGF binding to Met triggers receptor autophosphorylation and upregulation of Met kinase activity, which in turn stimulates a number of intracellular pathways mediating the biological effects of HGF, such as proliferation, motility, morphogenesis and angiogenesis. ${ }^{11}$ In normal cells, Met activation is tightly controlled by a ligand-dependent transient event, whereas in tumor cells, Met is often constitutively activated. ${ }^{12}$ Many different strategies have been exploited to inhibit aberrant Met signaling in various human cancer cells. These strategies target, directly or indirectly, the Met receptor and/or its ligand HGF. Direct methods include (1) HGF neutralizing antibodies or the use of the HGF antagonist NK4 or uncleavable proHGF to prevent ligand access to Met, ${ }^{13,14}$ (2) dominant-negative Met molecules, such as the recombinant sema domain of Met, decoy Met or anti-Met monoclonal antibody, ${ }^{15}$ (3) small molecule ATP binding site inhibitors, such as K252a, PHA-665752 and SU11274, to prevent Met kinase activity, ${ }^{16-18}$ (4) engineered SH2 domain polypeptides that interfere with access to the multidocking site ${ }^{19}$ and (5) shRNA or ribozymes that reduce receptor or ligand expression. $^{20}$ Most of these approaches display selective inhibition of Met signaling. Indirect inhibition of Met signaling can be achieved by blocking Met downstream signaling pathways, such as the MAPK, PI3K or STAT3 pathways, which contribute to the malignant features of Met. ${ }^{21}$

Recently, Horikawa et al. ${ }^{22}$ reported that EBV latent membrane protein-1 induced upregulation of the Met protooncogene, which is correlated with cervical lymph-node metastasis of NPCs. Qian et al. ${ }^{23}$ demonstrated that a high Met protein expression level correlates with poorer survival in late-stage NPC, and that the Met receptor in NPC is activated by its paracrine ligand HGF in the interstitial tissues rather than by an autocrine loop or an activating mutation.

Zhou et al. ${ }^{24}$ identified HGF-induced invasion and migration, which is mediated by JNK through regulation of matrix metalloproteinase (MMP)-9, in response to PI3K/Akt signaling in NPC cells.

Early growth response protein (EGR-1) is a nuclear protein that contains three zinc finger motifs in the DNA-binding domain and is activated by growth factors (e.g., epidermal growth factor (EGF) or HGF), cytokines, hormones and environmental stresses. EGR-1 also has an important role in the regulation of tumor angiogenesis and tumor growth. Recently, Cheng et al. ${ }^{25}$ have reported that EGR-1 was required for EGF-induced Slug expression involved in cell invasion in human ovarian cancer cells.

SAIT301, a novel Met antibody, was identified by Samsung Inc. (Yongin, Republic of Korea) and promotes LRR and immunoglobulin-like domain-containing protein 1 (LRIG1)mediated Met degradation in a Cbl-independent manner. ${ }^{26}$ In this study, we found that HGF-induced invasion and migration in NPC cell lines (HONE1 and HNE1) was inhibited by SAIT301, through downregulation of EGR-1 and Slug. Therefore, these results suggest that the Met monoclonal antibody, SAIT301, may be new anticancer therapeutic for controlling NPC progression and metastasis.

\section{Results}

Co-treatment with HGF and SAIT301 inhibits NPC cell migration and invasion. To examine the inhibitory effects of SAIT301 on the migration and invasion ability of HONE1 and HNE1 cells induced by HGF, we performed a wound-healing assay (Figure 1a) and a collagen-coatedtranswell-invasion assay (Figure 1b). As shown in Figure 1a, in the wound-healing assay, we scratched confluently growing HONE1 or HNE1 cells in 24-well plates and then pretreated with SAIT301 $(1 \mu \mathrm{g} / \mathrm{ml})$ for $1 \mathrm{~h}$, followed by HGF treatment for $24 \mathrm{~h}$. HGF induced narrowing of the scratch wound in both HONE1 and HNE1 cells; however, co-treatment with HGF and SAIT301 resulted in less cell migration than with HGF alone.

We further addressed the effect of SAIT301 on HONE1 and HNE1 cell invasion by using transwells, and found that co-treatment with HGF and SAIT301 significantly inhibited cell invasion compared with HGF alone (Figure 1b), indicating that SAIT301 inhibited HGF-induced NPC cell migration and invasion.

SAIT301 inhibits anchorage-independent growth induced by HGF in HNE1 cells. The soft agar colony formation assay has been used to measure anchorageindependent cell growth, a hallmark of cell transformation. ${ }^{27}$ To verify the inhibitory effect of SAIT301 on cell transformation in HNE1 cells, we performed the soft agar assay with or without HGF. As shown in Figure 2, HGF-stimulated HNE1 cells grew well in soft agar, but co-treatment with SAIT301 and HGF in HNE1 significantly decreased colony size and number. From this result, it was concluded that SAIT301 could inhibit the ability of cancer cell transformation.

HGF-elicited signal transduction pathways were inhibited by SAIT301. We next attempted to identify the inhibitory effect of SAIT301 on HGF/Met signal transduction pathways. SAIT301 considerably reduced Met tyrosine phosphorylation on pY1003, pY1234/1235 and pY1349 sites activated by HGF. Furthermore, we also analyzed the downstream signaling of Met. ERK and AKT activation was determined by immunoblotting using phospho-specific antibodies. As shown in Figure 3a, SAIT301 displayed significant inhibitory activity on $\mathrm{p}$-ERK, whereas the effect of SAIT301 was almost undetectable for p-AKT (Figure 3a). To confirm that Met degradation was induced by SAIT301, Met was visualized by immunocytochemistry to determine its cellular location before and after SAIT301 treatment. When cells were stimulated with $1 \mu \mathrm{g} / \mathrm{ml}$ SAIT301 for 0.5 or $1 \mathrm{~h}$, degradation of Met increased in the cytoplasm (Figure 3b). The results suggested that Met degradation by SAIT301 inhibited the activation of downstream signaling of HGF-Met.

HGF induces the expression of EGR-1 and Slug. Lai et $a .^{28}$ have demonstrated that EGR-1 expression is required for HGF-induced KLF4 upregulation and cell scattering. To further elucidate the molecular mechanisms through which HGF stimulates EGR-1 expression and Slug, we performed western blot analysis using antibodies against EGR-1 and Slug. HGF upregulated the expression of EGR-1 at $1 \mathrm{~h}$ and the expression of Slug from 3 to $6 \mathrm{~h}$ (Figure $4 \mathrm{a}$ ). Also to determine the inhibitory effect of SAIT301 on 
a

HONE1

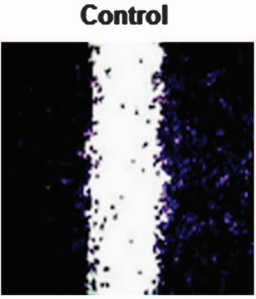

SAIT301
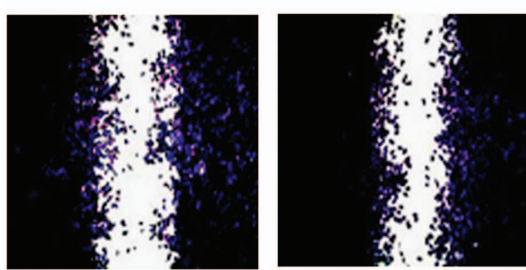

b

HONE1
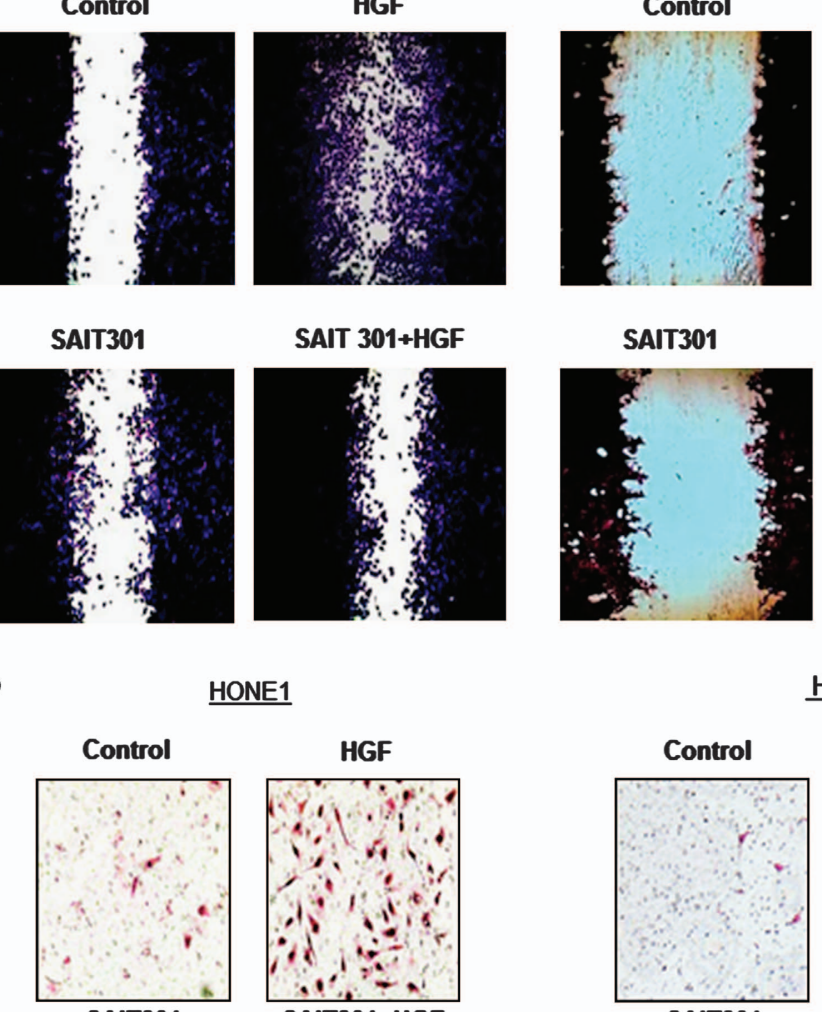

SAIT301
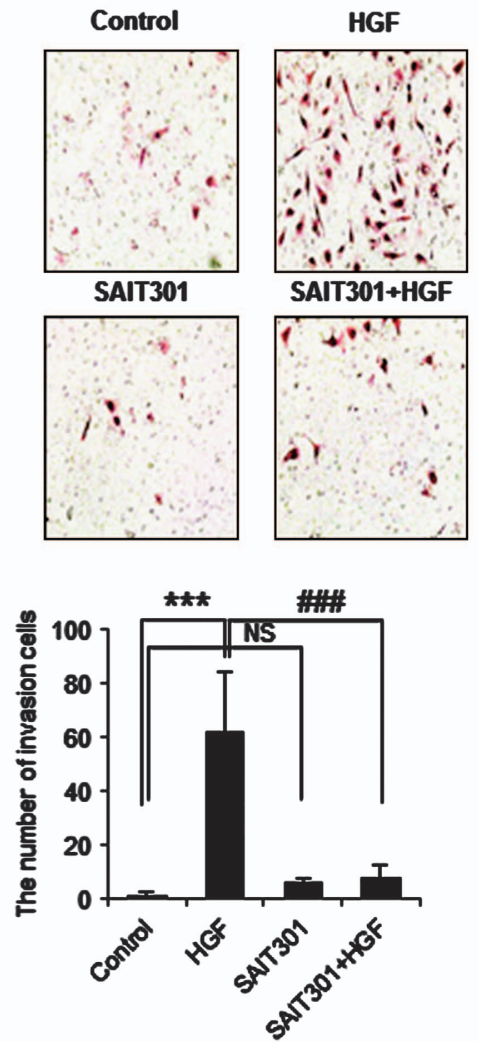

SAIT301

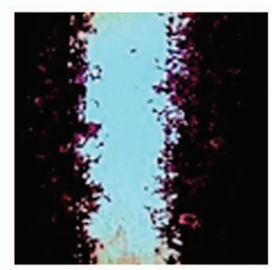

HNE1

HNE1

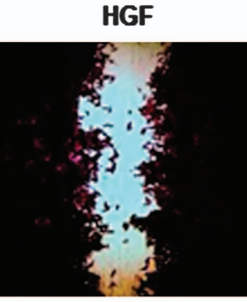

SAIT 301+HGF

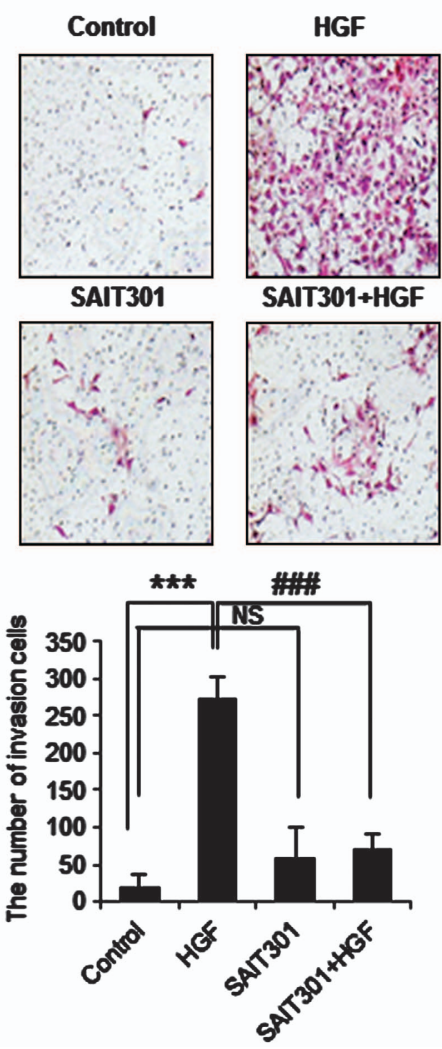

Figure 1 SAIT301 inhibited wound healing and invasion induced by HGF in HONE1 and HNE1 cell lines. (a) Wounds of confluent cells seeded in 24-well plates were generated using a sterile 200- $\mu$ l pipette tip in HONE1 and HNE1 cell lines. The cells were then washed with PBS and treated with HGF (30 ng/ml) alone or SAIT301(1 $\mu \mathrm{g} / \mathrm{ml})$ and HGF. (b) Cells were seeded in a collagen-coated transwell plate and incubated with $1 \%$ FBS medium with HGF alone or SAIT301 and HGF for $24 \mathrm{~h}$. After $24 \mathrm{~h}$, invading

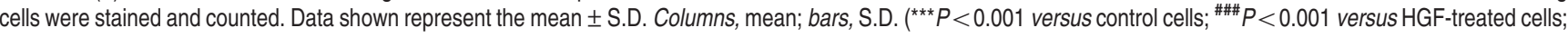
NS, not significant)

HGF-mediated EGR-1 and Slug expression, we pretreated with SAIT301 for $2 \mathrm{~h}$ before HGF treatment for $1 \mathrm{~h}$ in HONE1 and HNE1 cells, of which results interpreted that SAIT301 inhibited the HGF-induced expression of EGR-1 and Slug (Figures 4b and c).
Knockdown of EGR-1 reduces cell invasion induced by HGF in HNE1 cells. To examine the effect of HGF-induced EGR-1 expression on cell invasion, we specifically knocked down EGR-1 in HNE1 cells. After transfection for $24 \mathrm{~h}$, the transfected cells were seeded on collagen-coated transwells 


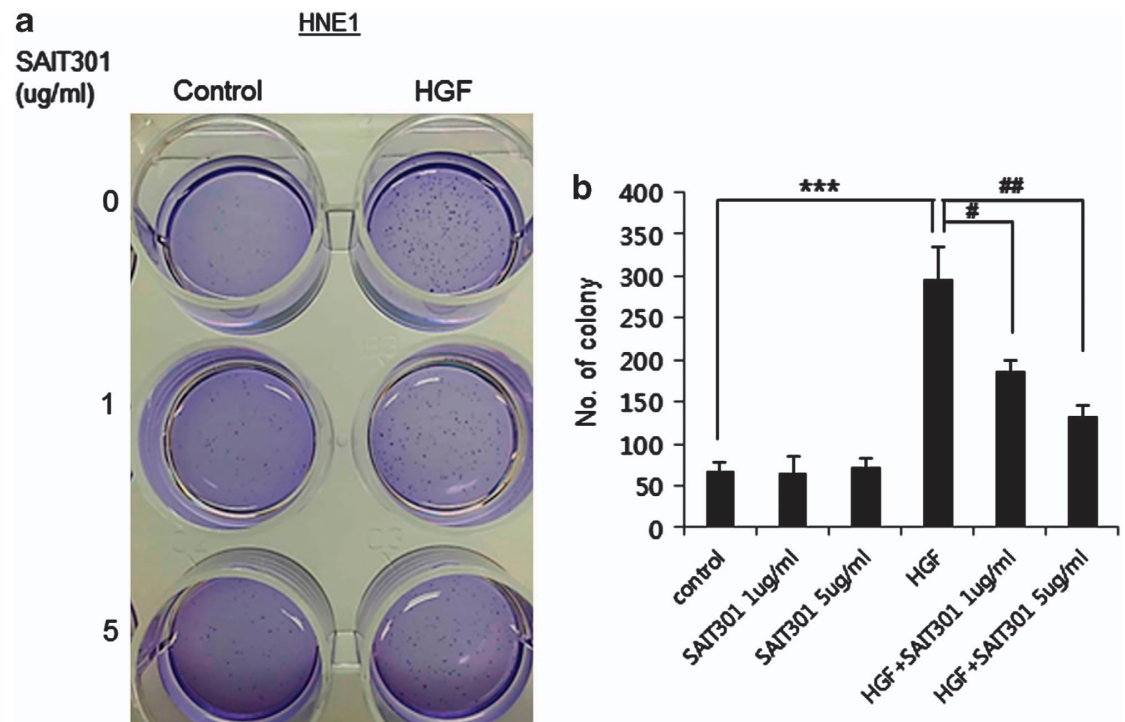

Figure 2 SAIT301 decreased the anchorage-independent growth induced by HGF in HNE1 cell lines. Soft agar assay in which cells were seeded at a density of $5 \times 10^{3}$ cells $/ \mathrm{ml}$ and cultured in $0.4 \%$ soft agar in DMEM plus $10 \% \mathrm{FBS}$ at $37^{\circ} \mathrm{C}$ for 21 days. HGF alone or SAIT301 and HGF were added to the soft agar every 3 days. After 3 weeks, the colonies were stained with $0.05 \%$ crystal violet. (a) representative plates. The stained colonies were counted using Metamorph NX image software (b) data shown represent the mean \pm S.D. Columns, mean; bars, S.D. ${ }^{* * *} P<0.001$ versus control cells; ${ }^{\# \#} P<0.01,{ }^{\#} P<0.05$ versus HGF-treated cells)

and then treated with SAIT301 alone, HGF alone or co-treated with SAIT301 and HGF. Invasion of EGR-1 small-interfering RNA (siRNA)-transfected cells was inhibited compared with control siRNA-transfected cells when treated with HGF (Figures 5a and b). Western blot analysis showed low expression of EGR-1 in EGR-1 siRNA-transfected cells compared with control siRNA-transfected cells (Figure $5 \mathrm{c}$ ). These findings explain that knockdown of EGR-1 inhibited HGF-induced NPC cell invasion, suggesting that the expression level of EGR-1 is important in HGF-induced invasion by NPC cells.

\section{Discussion}

Met is known to be overexpressed in oral, laryngeal and hypopharyngeal carcinomas in head and neck cancers. ${ }^{29-31}$ Kim et al. ${ }^{31}$ determined that the expression of HGF and Met was associated with lymph-node metastasis and the prognosis of patients with hypopharyngeal cancer. Lim et al. ${ }^{32}$ investigated the expression of Met associated with cancer invasion and metastasis by studying the clinical/pathological features of small squamous cell carcinoma of the oral tongue (SCCOT) patients and identified that the overexpression of Met promotes invasion of tongue cancer cells.

NPC is a highly invasive and metastatic tumor in many parts of the world. ${ }^{1}$ Binding of HGF to the extracellular region of Met triggers tyrosine autophosphorylation in the intracellular domain of Met and induces pleiotropic responses, such as proliferation, migration, invasion and angiogenesis in many types of cells. ${ }^{11}$ Therefore, the abrogation of HGF-Met receptor coupling or Met receptor-mediated signaling events appears to be a promising strategy for prevention of tumor metastasis.

Recently, Lee et al. ${ }^{33}$ identified a novel antibody, SAIT301, as a humanized anti-Met antibody that was originally developed from mouse immunization with a Met ectodomain and which promotes Met degradation in a Cbl-independent manner but exhibits minimal agonism. ${ }^{26}$ They also demonstrated that SAIT301 promotes LRIG1-mediated Met degradation. ${ }^{26}$ SAIT301-mediated Met degradation did not induce a significant agonism, further supporting the enhanced therapeutic potential of SAIT301. ${ }^{26}$ The aim of this study was to determine the inhibitory role of SAIT301, a Met monoclonal antibody, in NPC cell lines for cancer therapy. The results of this study conclude that SAIT301 inhibited HGF-induced invasion and migration in both HONE1 and HNE1 cells (Figure 1). At this point, the cell death effect of SAIT301 on HGF-induced invasion and migration can be questioned. In order for us to evaluate and prove further about its cell death and proliferation in this regard, we used other head and neck cancer cells as well as NPC cell line (HONE1 and HNE1) and confirmed the occurrence of neither cell death nor short-term proliferation (MTT assay) by treating SAIT301 at different concentrations for $72 \mathrm{~h}$ (Supplementary Figure 1). Therefore, we are suggesting that the cell death effect of SAIT301 on HGF-induced NPC invasion and migration is of little importance.

Looking at the overall results after multiple tests for the invasion by treating SAIT01, it was hard to see a significant invasion in NPC cancer cells, but rather SAIT single treatment caused a slight invasion. In fact, it showed a little activation of Met and Met downstream molecules whereas it exhibited much lower agonist activity than 5D5 (Genentech, Inc., South San Francisco, CA, USA) (e.g., phosphorylation of Met, AKT, Gab1 and other Met downstream cascade members, such as Shc, Stat1, ERK, Lck and Alk). ${ }^{33}$ Although it has been difficult to produce bivalent anti-Met antibodies due to the frequent agonism occurring at various degrees from the bivalency, ${ }^{34}$ SAIT301 has worked as an efficacious bivalent humanized monoclonal antibody with minimal agonism in spite of such challenging character and difficulties. 
a

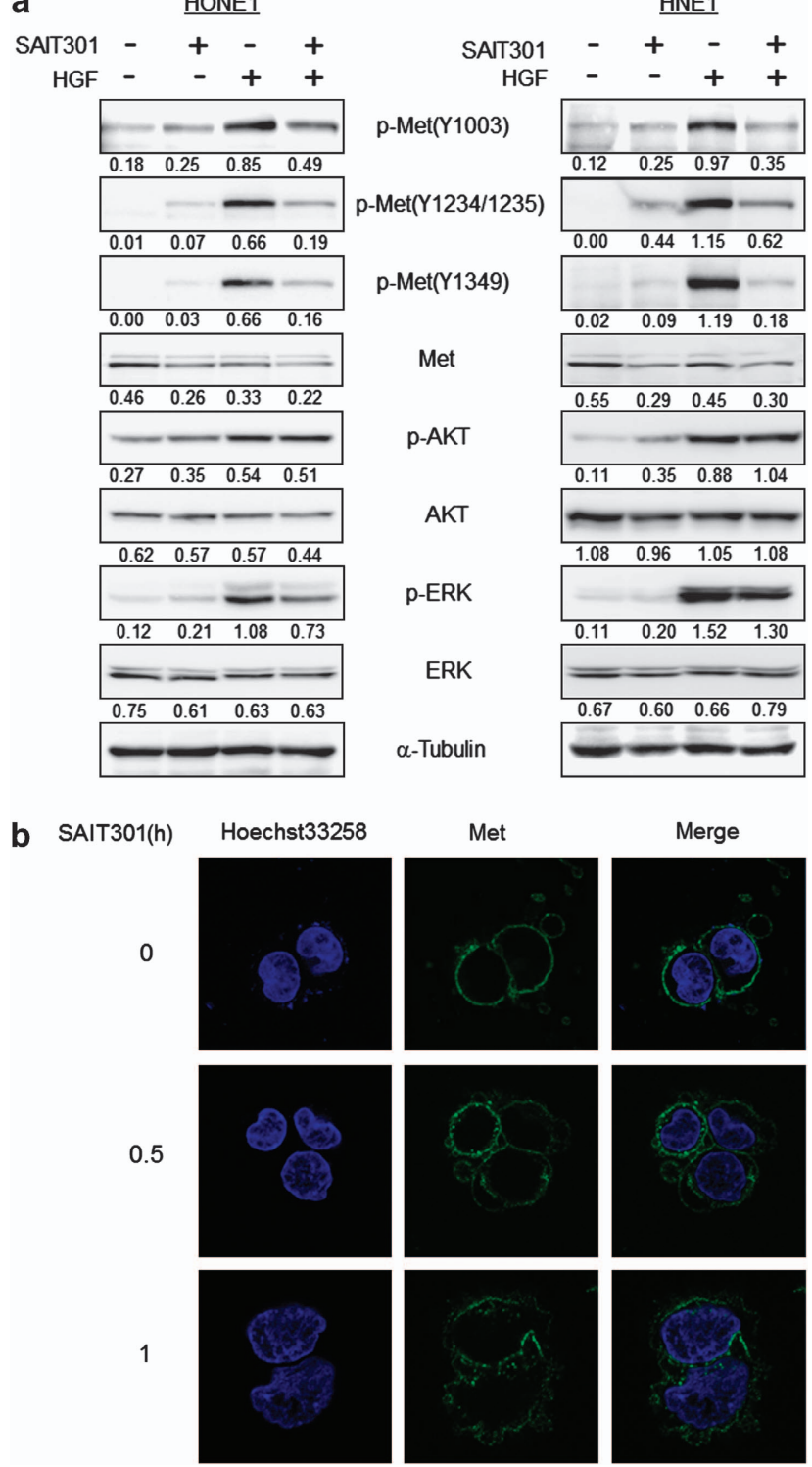

Figure 3 SAIT301 pretreatment inhibited the activation of Met and downstream signaling by HGF. (a) HONE1 or HNE1 cells were pretreated with $1 \mu \mathrm{g} / \mathrm{ml}$ SAIT301 for $2 \mathrm{~h}$ followed by treatment with $30 \mathrm{ng} / \mathrm{ml} \mathrm{HGF}$ for $10 \mathrm{~min}$. Cells were harvested and western blot analysis was performed for $\mathrm{p}$-Met, Met (upper band, precursor form of Met ( $170 \mathrm{kDa})$; lower band, mature form of Met (145 kDa)), p-ERK, ERK, p-AKT and AKT. $\alpha$-Tubulin was used as a loading control. (b) HONE1 cells grown on glass coverslips were treated with SAIT301 for 0.5 or $1 \mathrm{~h}$ and fixed by $4 \%$ paraformaldehyde for $15 \mathrm{~min}$. Cells on coverslips were then incubated with anti-Met antibody (Cell Signaling) at $4^{\circ} \mathrm{C}$ overnight. Image processing was performed using a Zeiss LSM 710 confocal microscope (Zeiss)

The prognosis of head and neck cancers depends on the metastasis that occurs in cancer cell migration and invasion. Therefore, NPC that is associated with the process is one of the key strategies to prevent cancer cells from migrating and invading. Although SAIT301 does not affect the cell viability or short-term proliferation (MTT assay) of NPC, it is found in the long-term proliferation of NPC on soft agar assay that SAIT301 slows down NPC proliferation and effectively reduces the migration and invasion, which can maximize the effectiveness of the treatment for NPC.
Also, as shown in Figure 2, HGF alone evidently increased the number and size of the cell colonies; however, cotreatment with HGF and SAIT301 decreased the number and size of colonies of HNE1 cells. Similar to our results, Li et al. ${ }^{35}$ reported that knockdown of Met using siRNA inhibits the survival, proliferation and invasion of NPC cells. Zhou et al. ${ }^{24}$ demonstrated that HGF, which is involved in the invasive phenotype and motility of NPC cells, is mediated by JNK through upregulation of MMP-9. However, we did not observe upregulation of MMP family genes induced by HGF in these cells.

Qian et al. ${ }^{23}$ demonstrated that a high level of Met protein correlates with poorer survival in late-stage NPC, and that the Met receptor in NPC is activated by its paracrine ligand HGF from the interstitial tissues rather than by an autocrine loop or its activating mutation. When we examined the expression of Met using western blotting and HGF using ELISA in both HONE1 and HNE1 cell lines, Met was highly expressed, but basal p-Met (Figure 3a) and HGF (data not shown) were rarely detected.

EGR-1 is rapidly activated by multiple extracellular agonists (such as growth factors and cytokines) and environmental stresses (such as hypoxia, fluid shear stresses and vascular injury). According to the report from Worden et al., ${ }^{36}$ EGR-1 is a downstream transcription factor that differentially regulates HGF-induced proangiogenic factors such as PDGFA and VEGF expression in head and neck squamous cell carcinoma. Fahmy et al. $^{37}$ have shown that silencing EGR-1 expression with DNAzymes significantly inhibited the breast cancer growth and angiogenesis in vivo. However, it has not been yet reported the effect of EGR-1 on HGF-induced NPC invasion and migration.

As seen in Figure 5b, the invasion of EGR-1 siRNAtransfected cells was inhibited, compared with the control siRNA-transfected cells when treated with HGF (Figure 5b). However, because the cells were incubated in serum-free condition, it is difficult to detect the cell invasion without HGF. Previously, we evaluated the significance of the serum HGF level in patients with HNSCC and found that the serum HGF level correlated significantly with the stage of the tumor progression. $^{38}$

Epithelial-mesenchymal transition (EMT) is an essential physiological process during the metastasis of cancer cells. Cancer cells can be induced to dissociate by being treated with growth factors (HGF, FGF, EGF and TGF families) through the change in expression of Snail, Slug or E-cadherin. Cheng et al. ${ }^{39}$ have reported that EGF downregulates E-cadherin expression by upregulating Snail and Slug expression in human ovarian cancer cells. Savagner et al. ${ }^{40}$ have reported the role and cell biological effects of the zinc finger protein Slug in FGF-1 or HGF-induced EMT such as desmosome dissociation, cell spreading, and the initiation of cell separation in rat bladder carcinoma cells. Also there is a research done by Huang et al. ${ }^{41}$ suggesting that the knockdown of LEF1 inhibited the expression of Slug and markedly attenuated HGF-induced tumor migration and invasion. However, it has not been elucidated the role of Slug in HGF-induced NPC invasion and migration.

While Grotegut et al. ${ }^{42}$ demonstrated that Snail has a critical role in HGF-mediated downregulation of E-cadherin and 
a
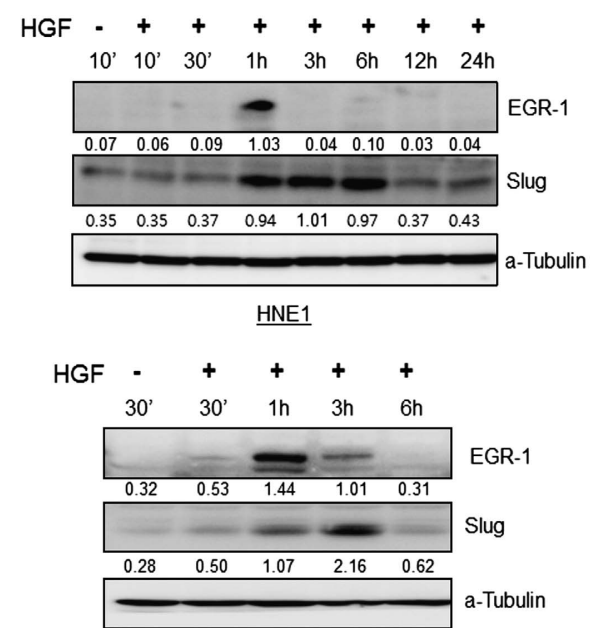

b

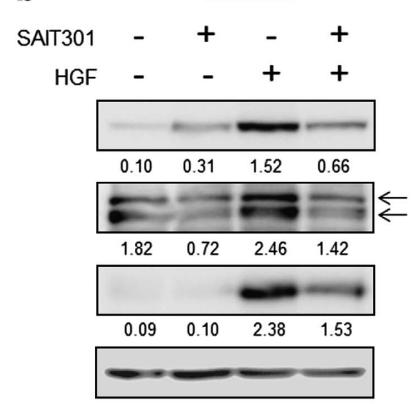

C
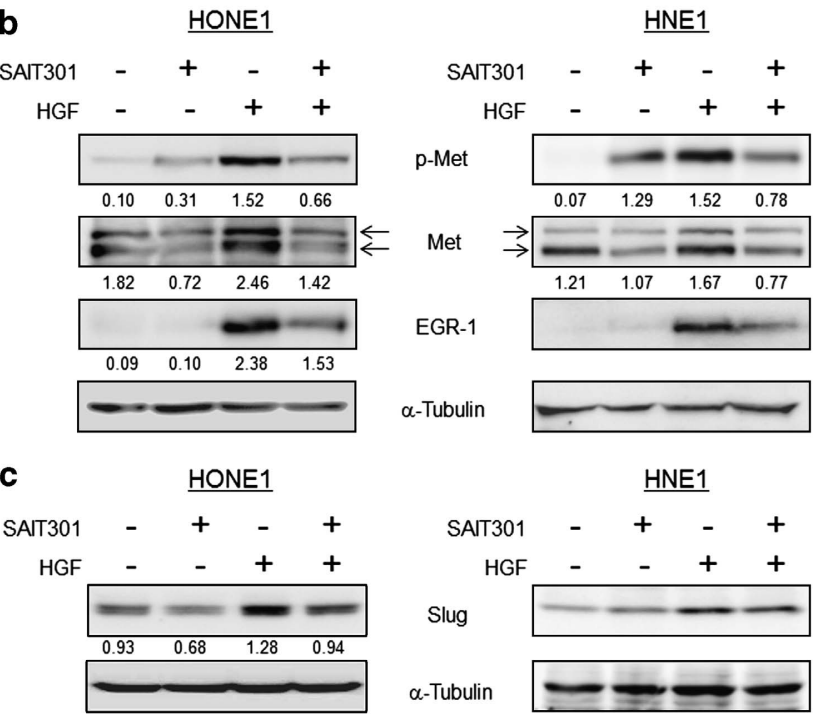

Met

$\rightarrow$

EGR-1

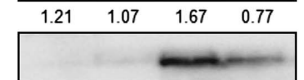

$\alpha$-Tubulin

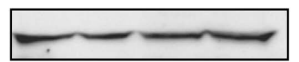

HNE1

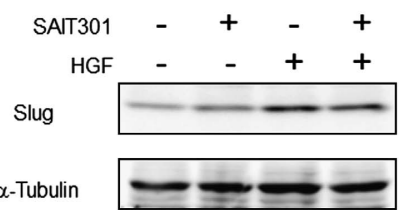

Figure 4 HGF induced the production of EGR-1 protein at $1 \mathrm{~h}$, and SAIT301 inhibited the HGF-induced production of EGR-1. (a) HONE1 or HNE1 cells were treated with $30 \mathrm{ng} / \mathrm{ml} \mathrm{HGF}$ for $10 \mathrm{~min}, 30 \mathrm{~min}, 1 \mathrm{~h}, 3 \mathrm{~h}, 6 \mathrm{~h}, 12 \mathrm{~h}$ and $24 \mathrm{~h}$. Cells were harvested and western blot analysis was performed using antibodies against EGR-1 and $\alpha$-Tubulin. (b and $\mathbf{c}$ ) HONE1 or HNE1 cells were pretreated with SAIT301 for $2 \mathrm{~h}$ before HGF treatment for $10 \mathrm{~min}$ and then harvested. Western blot analysis was performed for $p$-Met and EGR-1. $\alpha$-Tubulin was used as a loading control

claudin-3 expression, thereby promoting cell scattering, migration and invasion, we detected the expression of Slug induced by HGF in NPC cells, but not Snail (Figure 4c).

Lee et al. ${ }^{26}$ showed that SAIT301 binds to an extracellular region of Met, generating an intracellular signal, which is different from the signal of other antibody such as 5D5 when bound to Met. They suggested that SAIT301 has minimal agonism due to its implication in Cbl-independent Met degradation. Our findings demonstrate that Met degradation by SAIT301 inhibited HGF-induced invasion and migration in NPC cell lines (HONE1 and HNE1) and conclude that the Met monoclonal antibody, SAIT301, can be a new anticancer therapeutic for controlling NPC progression and metastasis.
Materials and Methods

Cell culture and reagents. The human nasopharyngeal cell lines HONE1 and HNE1 were provided by Dr. Ronald Glaser ${ }^{43}$ (The Ohio State University Wexner Medical Center, OH, USA). HONE1 cell lines were maintained in RPMI-1640 (Gibco/Invitrogen, Carlsbad, CA, USA) and HNE1 cell lines in Dulbecco's modified Eagle's medium (DMEM). The cell lines were maintained at $37^{\circ} \mathrm{C}$ and $5 \% \mathrm{CO}_{2}$ in media supplemented with $10 \%$ fetal bovine serum (Gibco/Invitrogen). SAIT301 was provided by Samsung Advanced Institute of Technology (SAIT) in the Republic of Korea. ${ }^{26}$ PBS was used as a solvent control.

Recombinant human HGF was purchased from R\&D System, Inc. (Minneapolis, MN, USA). Collagen Type I was purchased from Gibco/BRL, Inc. (Carlsbad, CA, USA).

Western blot analysis. Cell lysates were prepared and western blot analysis was performed as described previously. ${ }^{44}$ Western blot analysis was performed using the following antibodies: p-Met (pY1234/1235, pY1349, pY1003), Met, p-ERK, ERK, p-AKT, AKT, EGR-1 and Slug (Cell Signaling Technology, Beverly, MA, USA). Relative intensity of individual protein bands was measured using image $\mathrm{J}$, and the numbers represent the band densities normalized to $\alpha$-Tubulin from same sample.

siRNA or plasmid transfection. Transfection with siRNA was performed as described previously. ${ }^{45}$ HNE1 cells were transfected with EGR-1 siRNA (100 nM) using Lipofectamine 2000 (Gibco/Invitrogen). siRNA oligonucleotides were acquired from Genolution Pharmaceuticals (Seoul, Korea). The sense-strand sequences of siRNA duplexes were as follows: scrambled (as a control): 5'-ACGUGACACGUUCGGAGAAUU-3', EGR-1 siNRA: 5'-GCAUACCAAGAUC CACUUGCGGUU- $3^{\prime}$. After $24 \mathrm{~h}$ of siRNA transfection, the cells were changed to $1 \%$ low serum media for $24 \mathrm{~h}$ and pretreated with SAIT301 for $2 \mathrm{~h}$, followed by treatment with HGF for $1 \mathrm{~h}$.

Soft agar colony formation assay. HNE1 cells were diluted to $5 \times 10^{3}$ cells $/ \mathrm{ml}$ in $0.4 \%$ Noble agar solution in DMEM with $20 \% \mathrm{FBS}$. The cell suspension was added to each well of a 24-well plate on an underlayer of $0.8 \%$ Noble agar in DMEM with $20 \% \mathrm{FBS}$ at $37^{\circ} \mathrm{C}$. Fresh DMEM containing $0.2 \% \mathrm{FBS}$ with or without HGF $(30 \mathrm{ng} / \mathrm{ml})$ was added to the top of the soft agar and then cultured at $37^{\circ} \mathrm{C}$ for 21 days. The culture medium was changed twice per week with or without HGF. The colonies were stained with a $0.05 \%$ crystal violet solution (dissolved in $20 \%$ methanol) and the stained colonies were counted using the Metamorph NX image software (Molecular Devices, Sunnyvale, CA, USA). Each experiment was performed in triplicate.

Wound-healing assay. Cells were plated on 24-well plates and grown to confluency, followed by serum deprivation for $24 \mathrm{~h}$. Wounds were generated by using a sterile 200- $\mu \mathrm{l}$ pipette tip and washed with $1 \times$ PBS. Cells were then treated with SAIT301 and/or HGF for an additional $24 \mathrm{~h}$. Three wells per experimental treatment were examined at $\times 10$ magnification by light microscopy. Each assays were done triple.

Invasion assay. Cell invasiveness was evaluated using collagen-coated transwell membrane inserts (BD Biosciences, Palo Alto, CA, USA). HONE1 or HNE1 cells were plated on the insert. Both inserts and lower wells were treated with vehicle control (PBS), SAIT301 and HGF. After $24 \mathrm{~h}$, the cells in the insert were gently removed using a cotton swab. Cells on the reverse side of insert were fixed and stained with hematoxylin and eosin. The number of invading cells was counted in four representative fields per membrane by using light microscopy at $\times 40$ magnification. Each assays were done triple.

Immunocytochemistry. Cells grown on glass coverslips were fixed by $4 \%$ paraformaldehyde for $15 \mathrm{~min}$. Non-specific binding was blocked with $1 \%$ bovine serum albumin (BSA). Coverslips were then incubated with anti-Met antibody (Cell Signaling) at $4^{\circ} \mathrm{C}$ overnight. After three washes with PBS, the coverslips were incubated with the secondary FITC-conjugated goat anti-mouse IgG antibody diluted in PBS containing 1\% BSA, washed repeatedly with PBS and mounted. The nucleus was stained with Hoechst 33258 , and image processing was performed using a Zeiss LSM 710 confocal microscope (Zeiss, Jena, Germany) with a $\times 40$ water objective.

Statistical analysis. Statistical evaluation of the data was conducted using Student's $t$-test. Results were considered as statistically significant at $P<0.05$. 

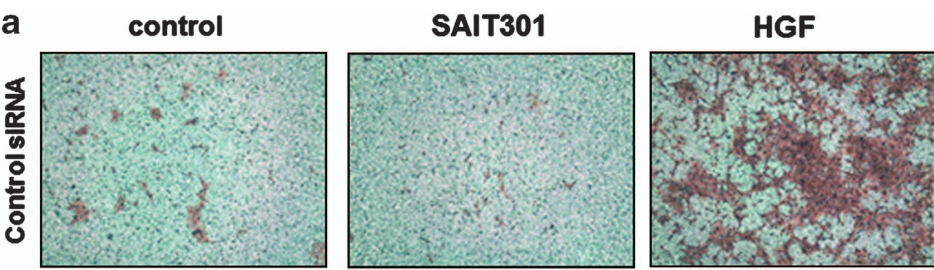

SAIT301+HGF
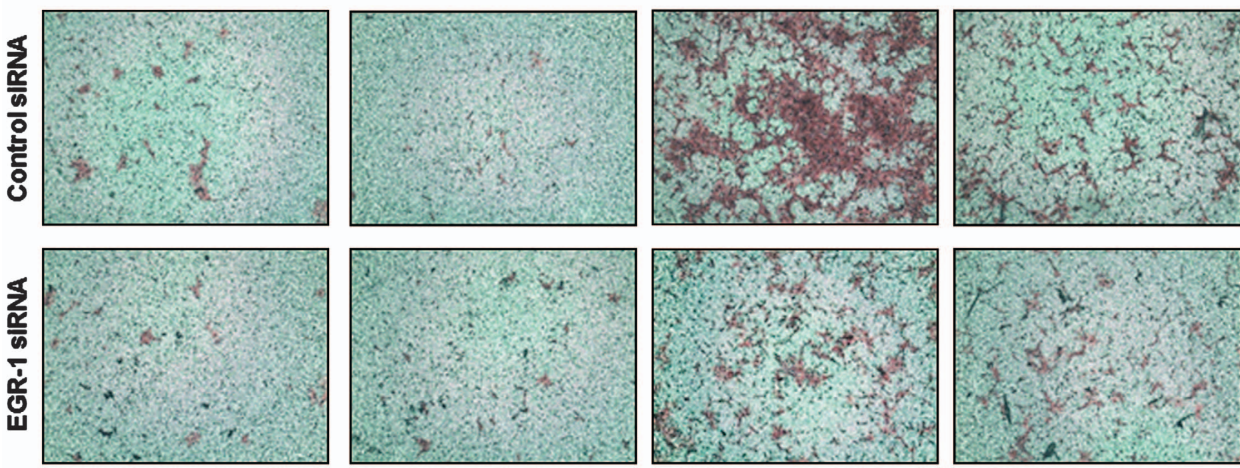

b
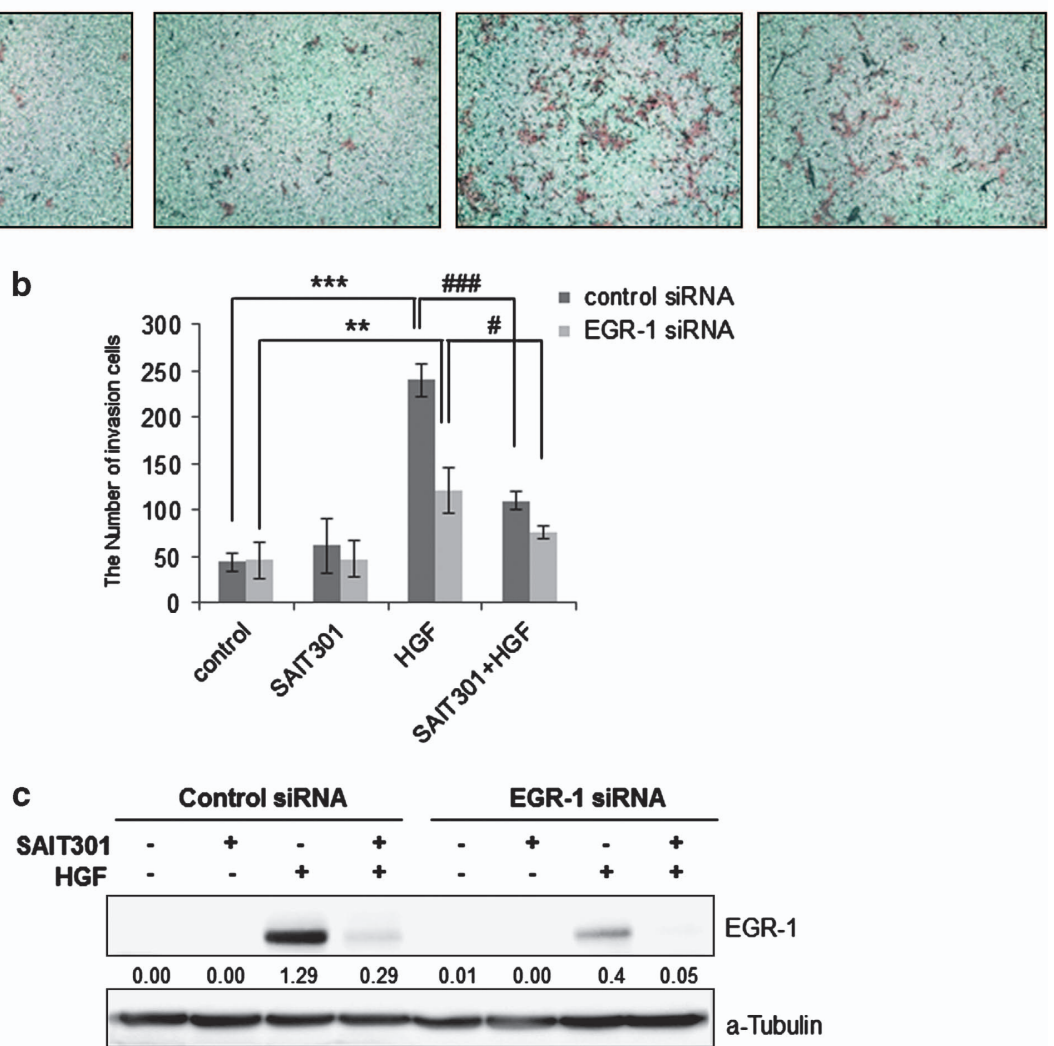

Figure 5 Knockdown of EGR-1 using siRNA decreased HGF-induced cell invasion of HNE1 cells. (a and $\mathbf{b}$ ) After $48 \mathrm{~h}$ of transfection with EGR-1 siRNA in HNE1 cells, the cells were seeded in a collagen-coated transwell plate and incubated with HGF $(30 \mathrm{ng} / \mathrm{ml})$ alone or SAIT301 and HGF for $24 \mathrm{~h}$. After $24 \mathrm{~h}$, invading cells were stained and counted. Data shown represent the mean \pm S.D. Columns, mean; bars, S.D. $\left({ }^{\star \star *} P<0.001,{ }^{* \star} P<0.01\right.$ versus control cells; ${ }^{\#} P<0.05,{ }^{\# \# \#} P<0.001$ versus HGF-treated cells). (c) EGR-1 siRNA-transfected HNE1 cells were pretreated with SAIT301 for $2 \mathrm{~h}$ before HGF treatment for $1 \mathrm{~h}$; cells were then harvested. Western blot analysis was performed for EGR-1. $\alpha$-Tubulin was used as a loading control

\section{Conflict of Interest}

The authors declare no conflict of interest.

Acknowledgements. This study was supported by a grant from the National Research Foundation of Korea (NRF) (2012R1A2A2A01013982) and by the Samsung Advanced Institute of Technology.

1. Yu MC, Yuan JM. Epidemiology of nasopharyngeal carcinoma. Semin Cancer Biol 2002; 12: $421-429$.

2. Farias TP, Dias FL, Lima RA, Kligerman J, de Sa GM, Barbosa MM et al. Prognostic factors and outcome for nasopharyngeal carcinoma. Arch Otolaryngol Head Neck Surg 2003; 129 : 794-799.

3. Chou J, Lin YC, Kim J, You L, Xu Z, He B et al. Nasopharyngeal carcinoma-review of the molecular mechanisms of tumorigenesis. Head Neck 2008; 30: 946-963.

4. Miller CL, Lee JH, Kieff E, Longnecker R. An integral membrane protein (LMP2) blocks reactivation of Epstein-Barr virus from latency following surface immunoglobulin crosslinking. Proc Natl Acad Sci USA 1994; 91: 772-776.

5. Yip KW, Mocanu JD, Au PY, Sleep GT, Huang D, Busson P et al. Combination bcl-2 antisense and radiation therapy for nasopharyngeal cancer. Clin Cancer Res 2005; 11 : 8131-8144.
6. Stoker M, Gherardi E, Perryman M, Gray J. Scatter factor is a fibroblast-derived modulator of epithelial cell mobility. Nature 1987; 327: 239-242

7. Park M, Dean M, Kaul K, Braun MJ, Gonda MA, Vande Woude G. Sequence of MET protooncogene CDNA has features characteristic of the tyrosine kinase family of growth-factor receptors. Proc Natl Acad Sci USA 1987; 84: 6379-6383.

8. Giordano S, Ponzetto C, Di Renzo MF, Cooper CS, Comoglio PM. Tyrosine kinase receptor indistinguishable from the Met protein. Nature 1989; 339: 155-156.

9. Gandino L, Di Renzo MF, Giordano S, Bussolino F, Comoglio PM. Protein kinase-c activation inhibits tyrosine phosphorylation of the Met protein. Oncogene 1990; 5 : 721-725

10. Naldini L, Vigna E, Narsimhan RP, Gaudino G, Zarnegar R, Michalopoulos GK et al. Hepatocyte growth factor (HGF) stimulates the tyrosine kinase activity of the receptor encoded by the proto-oncogene Met. Oncogene 1991; 6: 501-504.

11. Stella MC, Comoglio PM. HGF: a multifunctional growth factor controlling cell scattering. Int J Biochem Cell Biol 1999; 31: 1357-1362.

12. Danilkovitch-Miagkova A, Zbar B. Dysregulation of Met receptor tyrosine kinase activity in invasive tumors. J Clin Invest 2002; 109: 863-867.

13. Cao B, Su Y, Oskarsson M, Zhao P, Kort EJ, Fisher RJ et al. Neutralizing monoclonal antibodies to hepatocyte growth factor/scatter factor (HGF/SF) display antitumor activity in animal models. Proc Natl Acad Sci USA 2001: 98: 7443-7448.

14. Date K, Matsumoto K, Kuba K, Shimura H, Tanaka M, Nakamura T. Inhibition of tumor growth and invasion by a four-kringle antagonist (HGF/NK4) for hepatocyte growth factor. Oncogene 1998; 17: 3045-3054. 
15. Furge KA, Kiewlich D, Le P, Vo MN, Faure M, Howlett AR et al. Suppression of Ras-mediated tumorigenicity and metastasis through inhibition of the Met receptor tyrosine kinase. Proc Natl Acad Sci USA 2001; 98: 10722-10727.

16. Morotti A, Mila S, Accornero P, Tagliabue E, Ponzetto C. K252a inhibits the oncogenic properties of Met, the HGF receptor. Oncogene 2002; 21: 4885-4893.

17. Christensen JG, Schreck R, Burrows J, Kuruganti $P$, Chan E, Le $P$ et al. A selective small molecule inhibitor of Met kinase inhibits Met-dependent phenotypes in vitro and exhibits cytoreductive antitumor activity in vivo. Cancer Res 2003; 63: 7345-7355.

18. Inagaki Y, Qi F, Gao J, Qu X, Hasegawa K, Sugawara $Y$ et al. Effect of Met inhibitor SU11274 on hepatocellular carcinoma cell growth. Biosci Trends 2011; 5: 52-56.

19. Atabey N, Gao Y, Yao ZJ, Breckenridge D, Soon L, Soriano JV et al. Potent blockade of hepatocyte growth factor-stimulated cell motility, matrix invasion and branching morphogenesis by antagonists of Grb2 Src homology 2 domain interactions. J Biol Chem 2001; 276: 14308-14314.

20. Abounader R, Lal B, Luddy C, Koe G, Davidson B, Rosen EM et al. In vivo targeting of SF/HGF and Met expression via U1snRNA/ribozymes inhibits glioma growth and angiogenesis and promotes apoptosis. FASEB J 2002; 16: 108-110.

21. Birchmeier C, Birchmeier W, Gherardi E, Vande Woude GF. Met, metastasis, motility and more. Nat Rev Mol Cell Biol 2003; 4: 915-925.

22. Horikawa T, Sheen TS, Takeshita H, Sato H, Furukawa M, Yoshizaki T. Induction of Met proto-oncogene by Epstein-Barr virus latent membrane protein-1 and the correlation with cervical lymph node metastasis of nasopharyngeal carcinoma. Am J Pathol 2001; 159: 27-33.

23. Qian CN, Guo X, Cao B, Kort EJ, Lee CC, Chen J et al. Met protein expression level correlates with survival in patients with late-stage nasopharyngeal carcinoma. Cancer Res 2002; 62: 589-596.

24. Zhou HY, Wan KF, Ip CK, Wong CK, Mak NK, Lo KW et al. Hepatocyte growth factor enhances proteolysis and invasiveness of human nasopharyngeal cancer cells through activation of PI3K and JNK. FEBS Lett 2008; 582: 3415-3422.

25. Cheng JC, Chang HM, Leung PC. EGR-1 mediates epidermal growth factor-induced downregulation of E-cadherin expression via Slug in human ovarian cancer cells. Oncogene 2013; 32: 1041-1049.

26. Lee JM, Kim B, Lee SB, Jeong Y, Oh YM, Song YJ et al. Cbl-independent degradation of Met: ways to avoid agonism of bivalent Met-targeting antibody. Oncogene 2014; 33: 34-43.

27. Lee JH, Han SU, Cho $H$, Jennings B, Gerrard B, Dean $M$ et al. A novel germ line juxtamembrane Met mutation in human gastric cancer. Oncogene 2000; 19: 4947-4953.

28. Lai JK, Wu HC, Shen YC, Hsieh HY, Yang SY, Chang CC. Kruppel-like factor 4 is involved in cell scattering induced by hepatocyte growth factor. J Cell Sci 2012; 125(Pt 20): 4853-4864.

29. Murai M, Shen X, Huang L, Carpenter WM, Lin CS, Silverman S et al. Overexpression of Met in oral SCC promotes hepatocyte growth factor-induced disruption of cadherin junctions and invasion. Int J Oncol 2004; 25: 831-840.

30. Yucel OT, Sungur A, Kaya S. Met overexpression in supraglottic laryngeal squamous cell carcinoma and its relation to lymph node metastases. Otolaryngol Head Neck Surg 2004; 130: 698-703.

31. Kim CH, Moon SK, Bae JH, Lee JH, Han JH, Kim K et al. Expression of hepatocyte growth factor and Met in hypopharyngeal squamous cell carcinoma. Acta Otolaryngol 2006; 126 88-94.

32. Lim YC, Han JH, Kang HJ, Kim YS, Lee BH, Choi EC et al. Overexpression of Met promotes invasion and metastasis of small oral tongue carcinoma. Oral Oncol 2012; 48: 1114-1119.
33. Oh YM, Song YJ, Lee SB, Jeong Y, Kim B, Kim GW et al. A new anti-Met antibody selected by a mechanism-based dual-screening method: therapeutic potential in cancer. Mol Cells 2012; 34: 523-529.

34. Jin H, Yang R, Zheng Z, Romero M, Ross J, Bou-Reslan H et al. MetMAb, the one-armed 5D5 anti-Met antibody, inhibits orthotopic pancreatic tumor growth and improves survival. Cancer Res 2008; 68: 4360-4368.

35. Li Y, Zhang S, Tang Z, Chen J, Kong W. Silencing of Met by RNA interference inhibits the survival, proliferation, and invasion of nasopharyngeal carcinoma cells. Tumour Biol 2011; 32: $1217-1224$

36. Worden B, Yang XP, Lee TL, Bagain L, Yeh NT, Cohen JG et al. Hepatocyte growth factor/ scatter factor differentially regulates expression of proangiogenic factors through EGR-1 in head and neck squamous cell carcinoma. Cancer Res 2005; 65: 7071-7080.

37. Fahmy RG, Dass CR, Sun LQ, Chesterman CN, Khachigian LM. Transcription factor EGR1 supports FGF-dependent angiogenesis during neovascularization and tumor growth. Nat Med 2003; 9: 1026-1032.

38. Kim CH, Lee JS, Kang SO, Bae JH, Hong SP, Kahng H. Serum hepatocyte growth factor as a marker of tumor activity in head and neck squamous cell carcinoma. Oral Oncol 2007; 43: 1021-1025.

39. Cheng JC, Klausen C, Leung PC. Hydrogen peroxide mediates EGF-induced downregulation of E-cadherin expression via p38 MAPK and snail in human ovarian cancer cells. Mol Endocrinol 2010; 24: 1569-1580.

40. Savagner P, Yamada KM, Thiery JP. The zinc-finger protein slug causes desmosome dissociation, an initial and necessary step for growth factor-induced epithelialmesenchymal transition. J Cell Biol 1997; 137: 1403-1419.

41. Huang FI, Chen YL, Chang CN, Yuan RH, Jeng YM. Hepatocyte growth factor activates Wnt pathway by transcriptional activation of LEF1 to facilitate tumor invasion. Carcinogenesis 2012; 33: 1142-1148.

42. Grotegut S, von Schweinitz D, Christofori G, Lehembre F. Hepatocyte growth factor induces cell scattering through MAPK/EGR-1-mediated upregulation of Snail. EMBO J 2006; 25: 3534-3545.

43. Yang EV, Sood AK, Chen M, Li Y, Eubank TD, Marsh CB et al. Norepinephrine upregulates the expression of vascular endothelial growth factor, matrix metalloproteinase (MMP)-2, and MMP-9 in nasopharyngeal carcinoma tumor cells. Cancer Res 2006; 66: 10357-10364.

44. Lee BS, Cha HY, Shin YS, Kim YS, Kim CH. AY4, an agonistic anti-death receptor 4 MAB, induces apoptotic cell death in anaplastic thyroid cancer cells via downregulation of $\mathrm{Bcl}-\mathrm{xL}$ with reactive oxygen species generation. Endocr Relat Cancer 2013; 20: 283-291.

45. Lee BS, Kang SU, Hwang HS, Kim YS, Sung ES, Shin YS et al. An agonistic antibody to human death receptor 4 induces apoptotic cell death in head and neck cancer cells through mitochondrial ROS generation. Cancer Lett 2012; 322: 45-57.

(c) (i) $($ ) $\Theta$ Cell Death and Disease is an open-access journal (c) published by Nature Publishing Group. This work is licensed under a Creative Commons Attribution-NonCommercialNoDerivs 3.0 Unported License. The images or other third party material in this article are included in the article's Creative Commons license, unless indicated otherwise in the credit line; if the material is not included under the Creative Commons license, users will need to obtain permission from the license holder to reproduce the material. To view a copy of this license, visit http://creativecommons.org/licenses/ by-nc-nd/3.0/

Supplementary Information accompanies this paper on Cell Death and Disease website (http://www.nature.com/cddis) 